\title{
Construction and Practice of SPOC Teaching Mode
}

\author{
Shu-ying Chen * \\ Key Laboratory of Intelligent Information Processing \\ Shandong Technology and Business University \\ Yan Tai, China
}

\author{
Lei Chen \\ Coal Economy Academy \\ Shandong Technology and Business University \\ Yan Tai, China
}

\begin{abstract}
With the deepening of the application of information technology, MOOC has been widely popularized, and the traditional teaching mode is no longer suitable for the current university teaching. It is urgent to create SPOC based on MOOC for different learning situations. This paper analyzed the principles followed in the establishment of SPOC, and constructed the SPOC teaching mode in university teaching. By creating a three-stage teaching environment inside and outside the classroom, a general application framework was formed, which tried to provide abstract and theoretical reference for SPOC teaching practice in different colleges and universities. At the same time, the practice had been carried on the teaching application. The SPOC teaching mode was applied to the university teaching, and the application process of SPOC teaching mode was discussed in detail. In the process of practice, the deep integration of educational technology and subject teaching had been realized. The results showed that the teaching effect had been significantly improved.
\end{abstract}

Keywords-MOOC; SPOC; University Teaching; Traditional Teaching; Teaching Practice; Educational Technology

\section{INTRODUCTION}

College students in college classroom teaching have its own particularity. At present, most of the college students are post90s, the mind has basically matured, and the infused teaching is no longer suitable for the students learning needs.

The emergence of SPOC made the network teaching breakthrough the repeated school classroom stage and produced a more flexible, rich and effective learning effect [1]. Compared with MOOC alone, SPOC enables learners to experience a more complete learning process, SPOC developed teaching in campus physical classroom, customized courses for students, and provided learning support services that adapt to learners physical and mental characteristics, so as to make up for the problems and defects that MOOC can't solve [2]. At the same time, SPOC can embody the characteristics of small scale and big data, the teacher should give full play to the advantages of a large number of MOOC teaching resources and big data collected. SPOC learners share the same online courses with MOOC learners, showing differences in class size, teachers, and teaching processes. It can be seen that SPOC is the inheritance, perfection and transcendence of MOOC. SPOC emphasizes the advantages of utilizing MOOC resources, such as high quality, abundance and not limited by time and space, integrates it with university classroom teaching, and changes the emphasis on teachers' knowledge imparting in traditional classroom teaching. In order to improve the teaching quality,

This research was financially supported by Shandong University Cooperative Innovation Center: Future Intelligent Computing Cooperative Innovation Center. the teacher becomes the promoter and assistant of the students' study, and realized the interactive communication between the teacher and the students, stimulated the initiative and enthusiasm of the students' study, and realized the improvement of the teaching quality in light of the defects of the cultivation of the students' ability. It is necessary to construct a SPOC teaching mode to integrate the high-quality MOOC resources with the traditional campus environment effectively which is suitable for the college classroom.

The integration of information technology and curriculum is not simply the superposition of information technology and classroom teaching, but information technology as an effective means to promote students' cooperative exploration and interactive sharing by mobilizing students' independent enthusiasm for learning. Let the students' innovative thinking and the practice ability can be trained. The essence of the integration of information technology and subject curriculum is to reform the traditional teaching structure, reform the teachercentered teaching mode, and give full play to the "teacher ledstudent as the main body" teaching mode under the support of technology.

SPOC is the organic integration of MOOC and traditional teaching. It is an innovative application of MOOC localization in order to improve the teaching quality. Through flexible and effective activity design, MOOC learning and classroom teaching will be integrated into one, so that high-quality MOOC can assist classroom teaching, so as to expand the learning environment of students, enrich students' learning resources, and connect information exchange [3]. SPOC is a new teaching mode to improve teaching effect. In the SPOC teaching environment, students can choose classes freely through registration, listen to classes and discuss in the community, the system will give the exercise questions and scores according to the progress of class attendance, teachers can upload class videos, add teaching materials and exercises and so on through the system. It is worth emphasizing the online platform of the school which supports big data analysis of learning behavior and learning records in multiple dimensions, and teachers can monitor students' learning progress through big data analysis platform. Students can also more intuitively examine their own learning situation. 


\section{THE PRINCIPLE OF CONSTRUCTING SPOC TEACHING MODE IN COLLEGE CLASSROOM}

\section{A. The Principle of Student-Centered}

In the process of constructing the SPOC mode, the teacher should pay attention to the main position of the students and the individuation needs of the students, give the students personalized care throughout the whole process, and transplant the advantages of MOOC into the subject teaching. Let students choose learning methods freely according to their own circumstances and preferences. By using the flexible and free mode, the teacher can guide the active development of the students; give full play to the main role of the student center, and make up for the defects of the traditional teaching mode.

\section{B. The Principle of Flexible Activity Design}

Flexible activity design is the core of the successful implementation of SPOC teaching mode. It can't solidify the teaching process in the teaching practice and ignore the flexible and changeable characteristics of the teaching process. Otherwise, the advantages of the teaching mode will also become a disadvantage. The essential difference between MOOC and general online learning is that it has a complete learning experience. The biggest difference between SPOC and MOOC is that teachers make targeted instructional design according to the actual situation of the class. SPOC teaching mode is not simply the superposition of traditional classroom and MOOC, but the integration of MOOC resources and disciplines. The promotion of interest depends on teaching activities. The learning needs of the students can be met to the maximum extent [4].

\section{The Principle of Promoting Students Ability Development}

The cultivation of students' ability is the goal of the implementation of SPOC teaching mode. Under the background of the knowledge economy and lifelong learning, autonomous learning will embody more and more important value. Students self-study ability is one of the important abilities that college students need to have [5]. In traditional classroom teaching, teachers speak to students and form most students' passive and tired habit of listening to lessons. The passive installation often floats the understanding of knowledge on the surface. It is difficult to further internalize the understanding. The SPOC teaching mode emphasizes the importance of the self-study ability of students in the whole learning stage so that the students' self-control ability and learning ability can be achieved [6]. The implementation of SPOC teaching mode is expected to enable students to improve their self-study ability and lifelong learning ability while acquiring knowledge in long-term teaching practice.

\section{The Principle of On-Line Technology as Support}

SPOC is a small-scale application of MOOC in university teaching. MOOC provided on-line environment support for SPOC teaching mode, while online technology provided technical support for the implementation of SPOC teaching mode. Hybrid learning is a combination of the advantages of traditional learning and digital learning. The application of online technology in learning has many advantages. It complemented the online technology with the traditional faceto-face instruction, made use of the convenience, interactivity and Spatio-temporal separation of online learning, and constructed the SPOC teaching mode with online technology as the support.

The SPOC teaching implementation method based on the on-line technology includes the learning based on the multimedia video playing, the learning based on the on-line communication interaction, the learning based on the on-line browsing, the learning based on the on-line test. In the course of the implementation of the SPOC teaching, these learning methods are optimized according to the degree of learning.

\section{E. The Principles of Timely Evaluation and Real-Time Monitoring}

In the on-line learning stage, the teacher can know the students learning by technical means, such as voting, QQ group speech, short message interaction, etc. The student's online test and practice have the automatic evaluation function of the MOOC platform so that the students can obtain the evaluation result for the first time. On the classroom teaching stage, the teacher designs question part, which guides students to make a positive speech in the class; the practice of the classroom also gives the teachers and students adequate discussion and the opportunity to answer, the students' problem can be answered. In order to adjust the teaching schedule and direction in time, the two ways of line-on-line are combined to obtain the feedback of the students in time.

\section{THE IMPLEMENTATION PROCESS OF THE SPOC TEACHING MODE}

It is divided into task-based self-study before class, in-class active learning classroom and after-class spiral consolidation and promotion three stages.

In view of the course of teaching in colleges and universities, it is divided into the pre-class training stage, new class teaching stage, and post-class consolidation stage. According to the different characteristics of each stage, it is divided into three teaching modes: "pre-class integration mode", "class integration mode" and "after-class integration mode". The three stages of information technology and teaching process are respectively integrated and divided into three stages "pre-class integration mode", "in-class integration mode" and "after-class integration mode".

This stage is mainly carried out by self-study based on MOOC, It uses the resources of the MOOC platform and the teacher designs to complete the pre-class knowledge acquisition. MOOC resources have the advantages of high quality, convenience, repeatability, and so on. The teacher arranges the MOOC resources corresponding to the teaching content for the students to study before class and lays the foundation for the autonomous learning activities in the class.

The purpose of this stage is to leave the part of teaching new knowledge in the online self-study of students before class, and to reserve classroom time for students' task-based exercises and group cooperative learning, so as to achieve the integrity of the overall teaching. 


\section{A. Pre-Class Self-Study Stage Based on Learning Task}

1) Teacher behavior--arranging self-study tasks to get feedback from students

At this stage, the teacher is the guide and assistant of students learning. Although the students' study on MOOC platform is a complete learning process, the integration of MOOC and university subject teaching requires the teacher's localization design and guidance, and not just self-study according to the MOOC process. Before the students' selfstudy begins, teachers should design self-study task tables in accordance with the class teaching to guide the students' learning process on the MOOC platform. After the students finished the task of self-study, the teacher should get the feedback information of the students in time before class, in order to adjust the teaching design to suit the students' learning condition, and prepare for teaching according to their aptitude.

a) Analyzing the learning situation and arranging the online learning task

Before the class, teachers should set up the MOOC learning task table according to the teaching contents and teaching objectives of this lesson and the corresponding content of MOOC. The contents include: first, students watch online videos and discuss online topics. The study of handouts and online tests will enable students to complete the new knowledge of the course. Second, clarify the teaching objectives of this class, so that students can understand the ability requirements they want to achieve. Third, teachers arrange extended thinking questions to promote further understanding of new knowledge and thinking about the examination. support

b) Interactive questions and questions, online learning

In the process of student's online learning, teachers provide students with online answers to help them solve learning problems and overcome their lethargy. At the same time, students can also put forward their own ideas and suggestions; teachers can choose specific teaching activities and teaching content. Teachers monitor students learning progress online, and the teacher side of the MOOC platform provides SPOC class statistics that can be viewed at any time, including class access records and videos, and browsing records of courseware.

c) After the students have completed the task of selfstudy, teachers ask some simple questions to understand the actual situation of the students and the difficulties they encountered in the process of learning, so as to focus on the explanation and discussion in the class.

2) Students' behavior--learning new knowledge on-line and completing learning tasks

Under the guidance and assistance of teachers, students complete the task of MOOC self-study, master the teaching content, and lay the foundation for teaching activities in class.

a) In the pre-class stage, students learn autonomously on the MOOC platform according to the study task list assigned by the teacher. Watch MOOC video online to achieve the basic mastery of the teaching content, and save time to teach new knowledge in the final class. Because
MOOC learning is not limited by time and place, students can learn repeatedly according to their own situation until they fully understand, which can satisfy the students of different learning foundations and different learning styles.

b) Doing proper exercises to deepen knowledge understanding. After watching the MOOC video, students should do appropriate targeted exercises. In view of the knowledge in the MOOC video, the difficulty and quantity of the exercises should be reasonable from the two aspects of the exercises in MOOC and the after-class exercises in the textbook to select the parts suitable for the improvement of the students' ability in this class.

c) Real-time interaction, discussing learning problem. E-class learning exchange has the free selectivity of online learning. On the one hand, students can participate in an interactive discussion of subject topics with all the online learners taking part in the course through the online discussion section of the MOOC platform. On the other hand, real-time interaction within the SPOC class can be carried out through the class QQ group, and the learning problems and experiences encountered can be shared with teachers and classmates.

\section{B. Active Learning Class}

Classroom teaching is the most important part for students to learn, face-to-face teaching makes up for the shortcomings of online learning, and students become learning companions in the classroom. The whole class becomes an online and offline co-existing learning community. In the classroom teaching under SPOC teaching mode, it is necessary to break the traditional classroom passive indoctrination teaching method, through the design of teaching activities and the integration of technology and subject content. It needs to shift the focus of classroom activities to the internalization of students' knowledge and ability training, and improve the effectiveness of classroom teaching. The teacher changes from the lecturer to the organizer and assistant of the classroom activities and the student are the main body of the study. The design of the activities provides the conditions for the students to learn independently and learn collaboratively.

\section{The Spiral Consolidation and Promotion Stage after Class}

In the spiral consolidation and promotion stage after class, the students use MOOC to find out and fill the gaps in the knowledge they have learned, in order to expand the depth of knowledge understanding in the process of repeated learning and to improve the ability to use knowledge. After-class learning is not limited to this teaching period but extends to future learning. In the past, when there were loopholes in knowledge, errors in understanding, or forgetting of knowledge, students often gave up because no one explained it or was unable to get help. MOOC which is not limited by time When necessary, you can go back to watch teaching videos to browse learning forums. Students can get information, and consolidate the knowledge structure through the integration of future knowledge and program exercises, in order to have a deeper understanding of the previous study. 


\section{PROBLEMS AND IMPROVEMENT IN THE IMPLEMENTATION OF SPOC TEACHING MODE}

It is concluded that there were two main problems in SPOC teaching mode after a period of teaching practice, through observing students' learning behavior and analyzing students' feedback. First, MOOC learning was not closely related to classroom teaching; second, there was a lack of effective integration among the factors of mixed learning.

In view of these two main problems, the author made an appropriate adjustment to the SPOC teaching mode in order to better fit the students' learning characteristics and meets the learning needs. MOOC content review and difficult question answering, MOOC test question analysis and MOOC essence sharing link were added in the class stage, which made the study of MOOC more closely related to classroom teaching activities. The teacher selected the knowledge points and test exercises that the students found difficult in MOOC learning, and focused on explaining them to the whole class. Teachers and students discussed questions and answers in the MOOC activity area, absorbed different learning experiences outside the teaching materials, provided multiple angles to understand what they have taught, encouraged students to actively participate in MOOC online discussions, and shared their learning experiences. The essence of information technology and curriculum integration is to combine various teaching resources, various teaching elements and teaching links through combination, reconstruction, mutual integration and improvement of teaching quality. The design of this link is not only a useful supplement to the online learning stage, but also a systematic process of knowledge structure, so that online and offline learning activities can be effectively integrated and students' recognition of MOOC can be increased. The difficulty of learning tasks after class was increasing. Spiral promotion emphasizes not only the review and practice of the past learning content but also the students' challenge to themselves after completing the learning task. the students' cognition of the subject knowledge system is realized, and the understanding of their own defects has really realized the spiral improvement in the process of increasing the difficulty again and again. In this paper, SPOC teaching mode was applied to undergraduate teaching class to verify whether it has practical guiding significance. This paper used many methods to investigate and analyze the teaching situation and the reasons that affect the students' learning effect in the teaching class of computer major in colleges and universities. SPOC teaching mode was applied to class teaching. Students registered to join MOOC online learning and became an online learning community. The stage of knowledge transfer was completed through students' online self-study, and the stage of knowledge consolidation and application was completed through a series of teaching activities. Network technology provided a guarantee for the realization and optimization of SPOC teaching mode. Through the investigation and background data, it was shown that the students' investment in learning, the quality of questions and the degree of homework completion have been improved to a certain extent. The results of the interview showed that the students had a high degree of acceptance of the new teaching mode as a whole, such as deepening the degree of learning understanding, improving the enthusiasm of after-class self-study, richer curriculum resources to meet the personalized needs and so on. But at the same time, there are also some problems, such as the enthusiasm of online communication is not high, some students regard self-study as a burden and so on. In a word, the value of SPOC teaching mode has not been fully demonstrated, and the design of teaching activities and online learning support still need to be improved and improved in future practice.

\section{CONCLUSION}

This paper analyzed the principles of MOOC, constructed the teaching mode of MOOC, and attempted the SPOC teaching mode in the university classroom. Although the students had shown some recognition of the new mode, their research needed a process of repeated refinement and timeconsuming. At the same time, this study only took the students in one class of Computer College of Shandong Technology and Business University as the practical object, and the subjects involved were single and fail to explore the characteristics of SPOC learning mode in other fields. Further exploration is needed in subsequent studies.

\section{REFERENCES}

[1] Yu-feng Wang, Yan Ni and Jing Qiao, “The Research and Practice of Blending Learning in Data Structure teaching,” Office Automation, vol. 356, pp. 51-53, August 2015. (In Chinese)

[2] Hew K F and Cheung W S, “Students' and instructors' use of massive open online courses (MOOCs): Motivations and challenges," Educational Research Review, vol.12, pp. 45-48, December 2014.

[3] Jian-ying Guo, "MOOC and the Future of Higher Education in China," Journal of Higher Education Management, vol. 2, pp. 55-58, February 2014. (In Chinese)

[4] Yue-fen Wu, Bo Yang, Wen-bin Li and Xin Fang, “The Research and practice of Blended Learning Teaching of data structure,” Computer Knowledge and Technology, vol. 13, pp. 120-121, November 2017. (In Chinese)

[5] Chang Liu, Tao Peng, Lian-ying Sun and Chen Hong, "Research on Mixed Teaching Mode of Software Courses in Application-oriented Universities,” Journal of Beijing Union University, vol. 33, pp. 23-28, July 2019. (In Chinese)

[6] Ming-xing Zeng, Gui-ping Li and Qing-ping Zhou, "from MOOC to SPOC: Construction of a Deep Learning Mode,” China Educational Technology, vol. 11, pp. 28-34, November 2015. (In Chinese) 